\title{
How to increase cross border transmission capacity? A case study: Belgium
}

\author{
David Bekaert*, Student Member, IEEE, Leonardo Meeus*, Member, IEEE, Dirk Van Hertem*, Member, IEEE, \\ Erik Delarue ${ }^{\dagger}$, Bram Delvaux ${ }^{\ddagger}$, Gerd Küpper ${ }^{\S}$, \\ Ronnie Belmans* Fellow, IEEE, William D’Haeseleer ${ }^{\dagger}$, Kurt Deketelaere ${ }^{\ddagger}$ and Stef Proost ${ }^{\S}$ \\ *Department of electrical engineering, ELECTA group, K.U. Leuven \\ Kasteelpark Arenberg 10, PB2445, 3001 Heverlee, Belgium \\ Tel: (+32) 16 321020, fax: (+32) 16321985 \\ e-mail: david.bekaert@esat.kuleuven.be \\ ${ }^{\dagger}$ Department of mechanical engineering, TME group, K.U. Leuven \\ ${ }^{\ddagger}$ Faculty of economics, ETE group, K.U. Leuven \\ $\S_{\text {Faculty of law, IMER group, K.U. Leuven }}$
}

\begin{abstract}
Cross border capacity allows electric energy to be traded internationally. The electricity sector used to be vertically integrated and often state-owned. High voltage grids were generally developed within the borders of a country. Connecting different national high voltage grids was done to improve the security of the system and to accomodate for a few historical long term contracts. By doing so, the different systems could share their reserve generation capacity. Since the liberalization of the electricity sector, cross border capacity has gained a renewed interest as this can increase the competition in the market. This paper aims to give an overview of recent and planned investments which increase the cross border capacity of Belgium. Also we give an insight into the different technologies which can be used and their advantages and drawbacks are discussed.
\end{abstract}

Index Terms-Cross border capacity, transmission investments, overhead lines, phase shifting transformer, HVDC

\section{INTRODUCTION}

Currently the high voltage grid of Belgium is interconnected with the high voltage grid of the Netherlands and France. There are three transmission lines between Belgium and France at $380 \mathrm{kV}$ and two transmission lines at $220 \mathrm{kV}$ level. Together they offer a total physical capacity of 5055 MVA. There are four $380 \mathrm{kV}$ cross-border lines to the Netherlands, which adds up to a physical capacity of 6070 MVA [1]. In figure 1 the Belgian high voltage grid is represented. Note that there is no connection with Germany. Luxembourg is not considered as a separate region, half of its high voltage grid is controlled by the Belgian transmission system operator, Elia, the other half by the German operator, RWE-Netz.

It is often mentioned that increasing the cross border capacity increases competition. This papers deals with measures that could increase this cross border capacity. For a thorough discussion on the effect of cross border capacity on the electricity market, see Küpper et al. [2].

Increasing cross border capacity can be done by building new lines or by installing so called power flow controlling devices. These are devices which allow controlling the flow through a line in order to optimize the overall flow in the grid.
In the following section it is explained how new overhead lines and underground cables can increase the cross border capacity. In the third section the effectes of power flow controlling devices is clarified. This is done by means of projects and studies carried out by Elia, the Belgian transmission system operator (TSO). In the last section it is explained how the value for the capacity available for the market is obtained.

\section{ADDING A NEW TRANSMISSION LINE}

\section{A. Overhead lines and cables}

In 2005 the interconnection capacity between France and Belgium was increased by the reinforcement of a line. This reinforcement was realized by installing a second circuit on the existing Avelin-Avelgem connection. Reinforcement was possible because back in 1974, although only one circuit was planned, there was opted for pylons which could carry a double circuit. The second circuit became operational on November 26, 2005. This line, with a rated capacity of 1450 MVA, connecting the region of Kortrijk (B) with Lille (Fr), provides between $700 \mathrm{MW}$ and $1000 \mathrm{MW}$ of additional transmission capacity. The capacity before this upgrade ran up to an average of $2200 \mathrm{MW}$. Note that the transfer capacity is not a fixed figure, but depends on several aspects (see further on in this section and in section IV. The total cost of this reinforcement amounted up to 15.7 million Euro [3].

The construction of a new overhead line seems to be the most obvious way to increase cross-border capacity. This classic approach of upgrading the electricity grid has been used since almost a century in the electricity industry and is therefore, very well known and understood. Besides this, no other technology can compete with the relatively low cost of such a classic overhead line.

If possible, increasing the capacity of existing trajectories is preferred. This can be done, as in the Avelin-Avelgem case, by adding another circuit to the pylons. Of course the pylons need to be suited for this solution. Another option for increasing the capacity is to replace the existing conductors with ones with a higher capacity. Again, this is only possible when the 


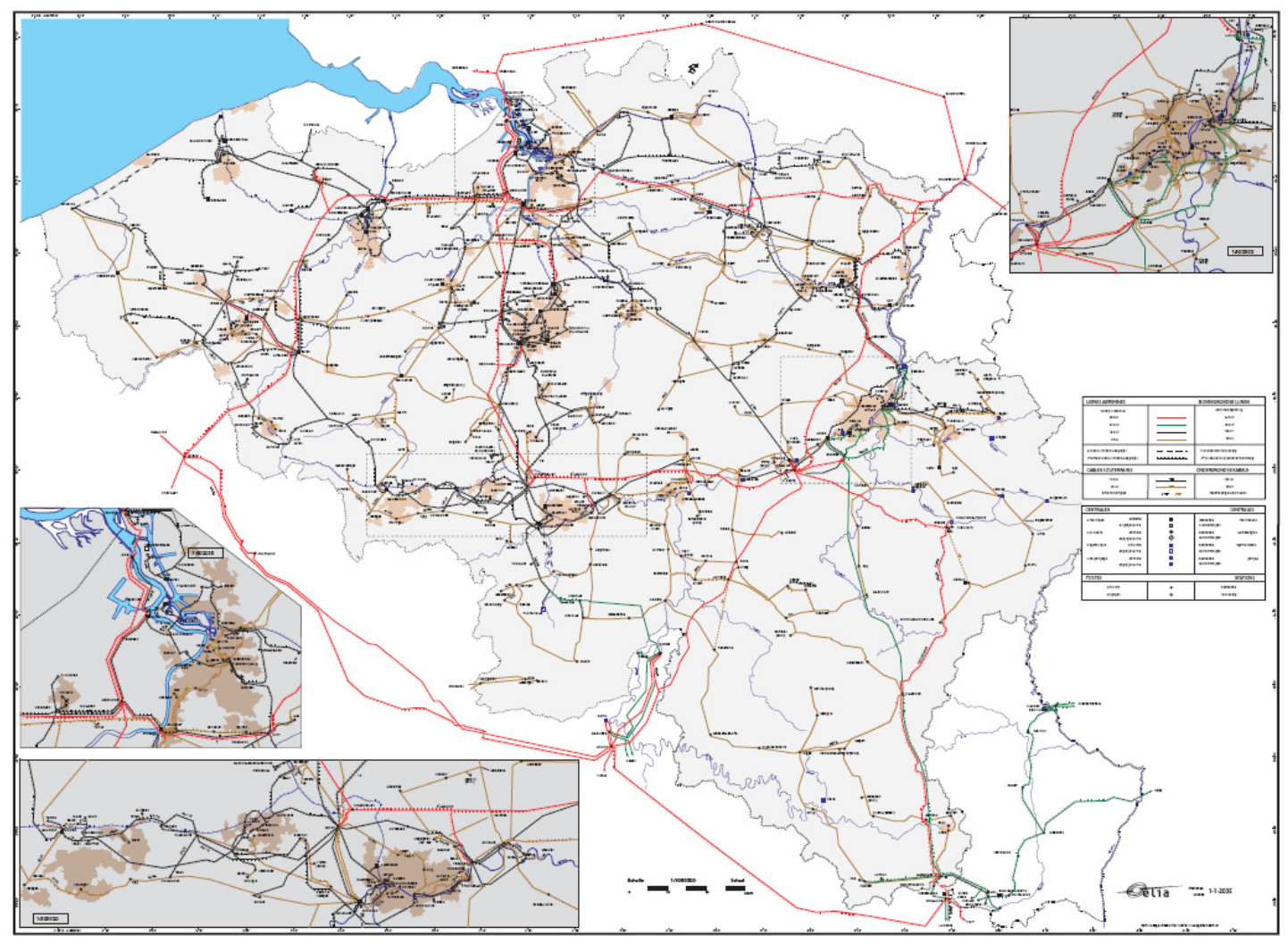

Fig. 1. The Belgian high voltage grid

pylons can carry the possible higher weight of the lines. Both options have proven to be a good solution for increasing the transmission capacity with AC technology. Furthermore the same trajectories as in the existing situation can be used, and thus protests of locals along the trajectory and the not in my backyard syndrome can be avoided.

If using an existing trajectory is not an option, a new trajectory needs to be found. This often invokes a lot of opposition. Apart from political and public resistance, the construction of new overhead lines also has an environmental impact. Other aspects, such as effects on vegetation, town centers, cultural heritage, etc. have to be taken into account. Therefore, planning and construction of a new overhead line following a new trajectory is usually accompanied from a very long permitting process ( 3 years to 15 years). In case of international interconnections, this permitting process can even be longer because of different regulations and the difficulty for financing international connections from national tariffs.

Next to the traditional overhead line, underground cables are an option. Compared to overhead lines, cables offer a good solution to avoid the problems described in the previous paragraph. The necessary use of land and visual pollution is less. A big drawback of underground cables is the cost, which is considerably higher than these of overhead lines. The cost ratio overhead lines / cables is estimated to be $1 / 7$ to $1 / 3$ below $150 \mathrm{kV}$, but at $380 \mathrm{kV}$ the ratio is estimated to be $1 / 10$ to $1 / 20$ [4]. A second problem is the high capacitance of an underground cable, which leads to operational problems and for longer distances (more than $20 \mathrm{~km}$ at $380 \mathrm{kV}$ extra) compensation is needed. A substation has to be installed with inductances for compensating the capacitive reactive power. Therefore because of economic and technical reasons, underground cabling at $380 \mathrm{kV}$ is exceptional. The mean time between failure of underground cables is much better than of an overhead line, as it is not exposed to external influences (e.g. lightning). However the time to find and repair the fault in an underground cable is considerably longer.

The capacity of a line is limited by its temperature. When a line is loaded, its temperature increases. In case of underground cables the capacity is limited by the amount of heat which can be evacuated in order to limit the temperature of the insulation material and thus avoiding permanent failures. For overhead lines the sag, caused by expansion (caused by the increased temperature), sets the maximum capacity of a line. This maximum capacity is often referred to as the thermal capacity or thermal rating. As in summer ambient temperature is higher a smaller increase in temperature, and thus loading, can be achieved before a critical point is reached. Hence it is also easy to understand why thermal capacity of overhead lines in winter is higher than in summer.

\section{B. Impact of a new transmission line on the transfer capacity}

When a new transmission line is installed between two zones, whether overhead line or cable, the total transfer capac- 
ity is not increased by the thermal capacity of the new line. As the Kirchoff laws state, the current divides itself over parallel paths inversely proportional to the reactance of the lines. The reactance of a line is an electric characteristic of a transmission line, depending on the length, the cross section, and the chosen material and geometry of the line. The reactance also depends on how the line is constructed and whether it is an overhead line or an underground cable. Therefore, parallel lines with the same thermal capacity seldom have the same impedance, and thus carry different power flows.

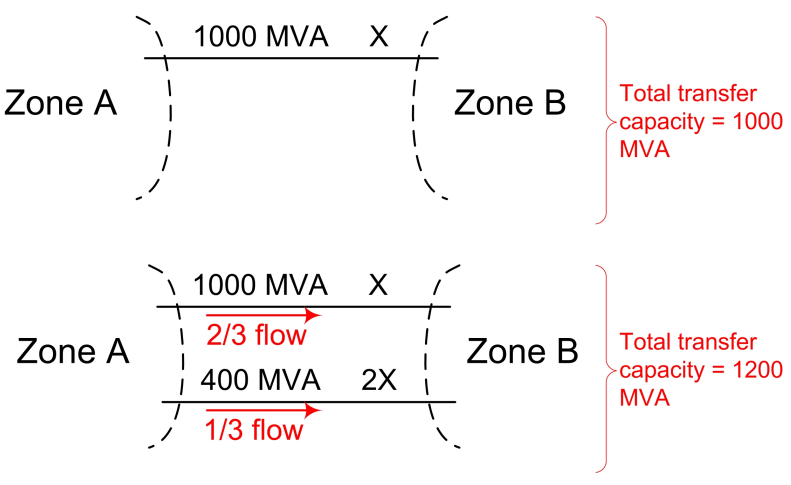

Fig. 2. Adding a parallel line

The effect of adding a transmission line on the total transfer capacity is illustrated in 2 . In the first case, there is only one line, with a thermal capacity of 1000 MVA between two zones. The reactance of this line is $\mathrm{X}$. The total transfer capacity between the two zones is defined by the capacity of the line. In the second case, a parallel line, with a thermal capacity of $400 \mathrm{MVA}$, is added in order to increase the total transfer capacity. The reactance of the new line is double the reactance of the existing line, thus $2 \mathrm{X}$. This is the case when for example the second line is twice as long as the first line. Because the distribution of the power flow over the two lines is inverse proportional to the reactance, one third of the current flows through the new line. When increasing the flow between the two zones, the thermal capacity of the second line is first reached. At that moment only $800 \mathrm{MVA}$ is flowing through the first line. Further increasing the flow between both zones is not possible, as the thermal rating of the second line would be violated. Although a line with a thermal rating of $400 \mathrm{MVA}$ was added, the total transfer capacity only increased with 200 MVA.

The example above is a thoroughly simplified, but it gives a fairly good idea what happens in reality. As mentioned earlier in this section, in the Avelin-Avelgem case a $380 \mathrm{kV}$ circuit was added. A typical thermal rating for a $380 \mathrm{kV}$ line is 1450 MVA. After installation of this line, practice proves that the total transfer capacity between Belgium and France increased by only 700 MVA to 1000 MVA.

The total transfer capacity is not necessarily equal to the capacity available to the electricity market. One should also take into account reliability margins, which allows the TSO to operate its grid in a reliable way. The determination of the

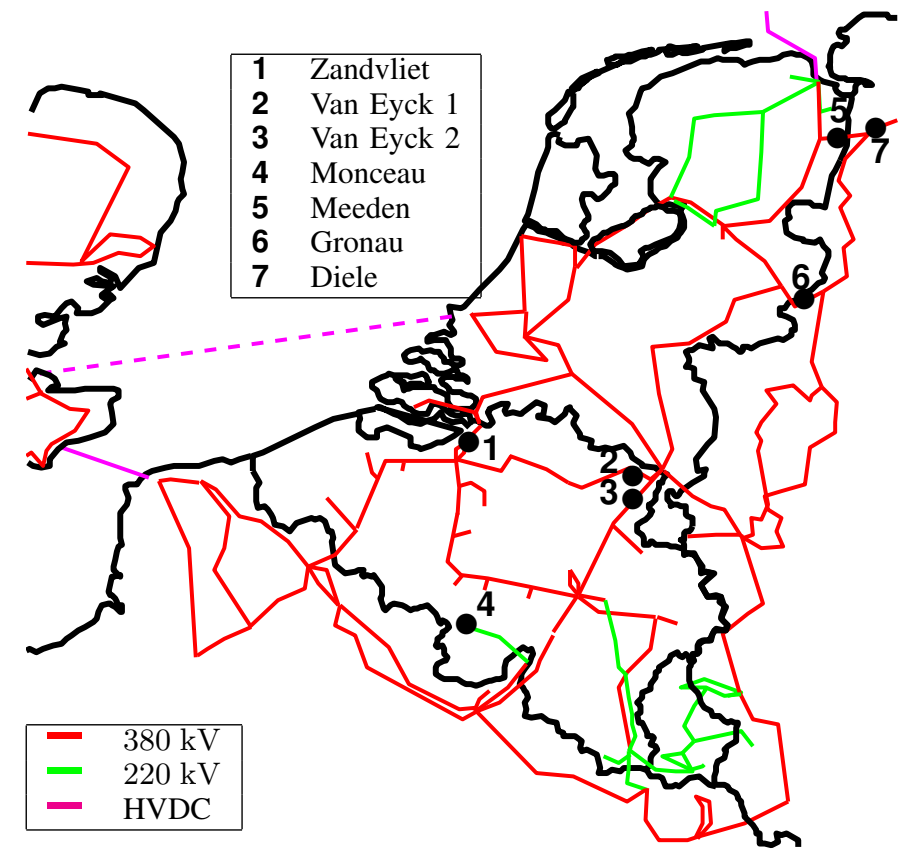

Fig. 3. Schematic overview of the placement of existing and projected PSTs in the Benelux transmission system [5]

capacity available to the market is further discussed in section IV.

\section{ADDING POWER FLOW CONTROLLING DEVICES}

Next to the above described technologies there are the so called power flow controlling devices to increase the transfer capacity. In contrary to the situation described in the previous example these devices allow to control the flow in an active way. The two most known devices are the phase shifting transformers (PSTs) and high voltage direct current (HVDC) lines.

\section{A. Phase shifters}

A PST is an electro-magnetic device that is introduced in an existing transmission line. It allows the TSO to control the power flow through a transmission line. Using these devices, the flow through heavy congested lines can be reduced and shifted to transmission lines with spare capacity. This means that the transfer capacities rise as congestion diminishes. Furthermore, PSTs are relative inexpensive devices, when compared to new transmission lines, that can often be placed in an existing substation. They are thus far less subject to public opposition due to environmental, political or other concerns. As a result, the permitting process for a PST may be short.

If in the example of the previous section a PST would be installed on the second line, the power could be shifted away from that line to the first one. In this way the total transfer capacity between zone A and B is increased.

In Belgium there is one PST installed near the border with France and three PSTs at the border with the Netherlands (Figure 3). The philosophy of these installations differs. 


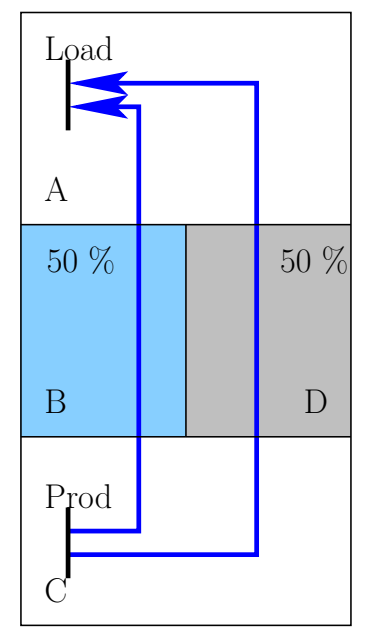

(A)

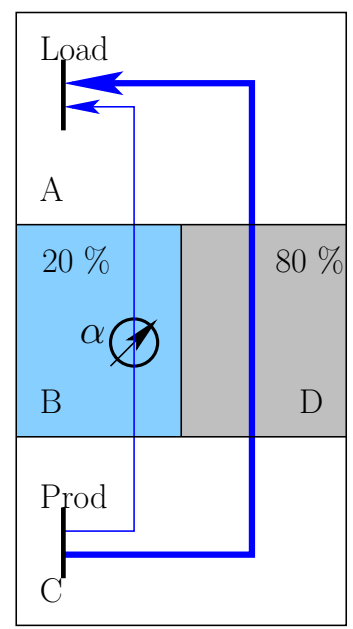

(B)

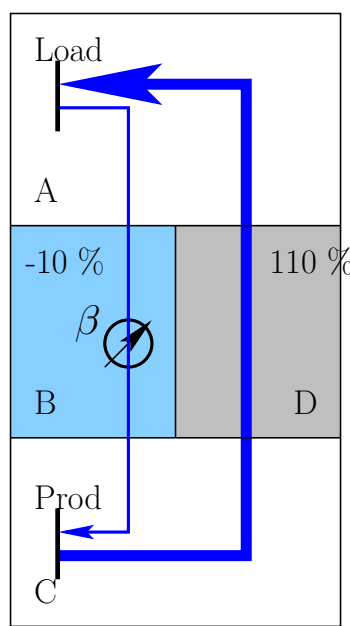

(C)

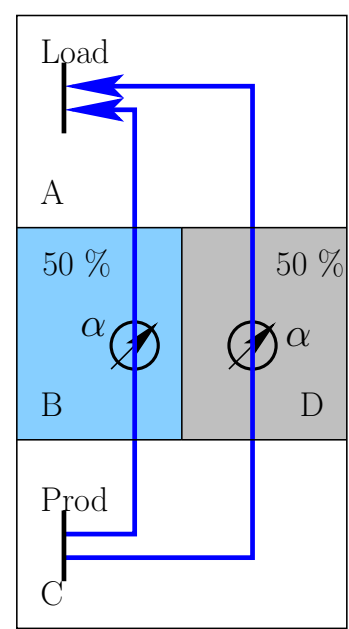

(D)

Fig. 4. Influence of a phase shifter on flows [5]

Load flow studies revealed that the $220 \mathrm{kV}$ line between Chooz (Fr) and Monceau (B) (close to point 4 in figure 3) could get overloaded in case of failure or maintenance of neighboring systems. Furthermore this line was the bottleneck for the transmission capacity between France and Belgium. Therefore it was decided to install a PST on this line in order to redistribute a part of its load on this line to other less loaded interconnections [6].

Together with the installation of this PST, a grid reinforcement took place. The double circuit on this line was upgraded from $150 \mathrm{kV}$ to $220 \mathrm{kV}$. Both investments increased the commercial interconnection capacity by $300 \mathrm{MW}$ [7]. The total cost of this investment is estimated at 10 million euros.

At the Dutch-Belgian border three PSTs are installed. Elia equipped every line between the Netherlands and Belgium with a PST. In this way the Belgian TSO can control the cross border flow. Transit flows from the north of Germany, where a lot of wind power is installed, to France cause loop flows through the Benelux. Loop flows are unintended flows through a non-contracted, parallel path. These loop flows create an additional loading on the Dutch and Belgian high voltage grid and can lead to critical situations. The installed PSTs along the northern border give Elia, the Belgian TSO possibilities to manage these flows.

A PST however also has some drawbacks. Firstly, it adds extra series element in the grid, subject to failure. Secondly it generally increases the losses in the system as it "distorts" the natural flows in the power system. Thirdly, the effects of power flow control are not necessarily positive for all parties involved. The effect of shifting the power flow is not local, and an increase in one place can induce a decrease in the other. A final disadvantage is that in case of multiple power flow controlling devices they must be used in a coordinated way in order to avoid inefficient grid use.

When multiple power flow controlling devices are installed in the transmission grid, local control can cause suboptimal or inefficient use of the available power system. Problems that can arise when dealing with power flow controlling devices are shown in 4.

Case A depicts the base case, where a simple four zone example is given, with a netto generation in zone $\mathrm{C}$ and a netto load in zone A. Both flow paths cross zones B and D respectively, both with an equal share of the load.

Case B gives the situation after implementing a power flow controlling device in zone B. $30 \%$ of the flow is shifted from the path through $\mathrm{B}$ to the path through $\mathrm{D}$. This case is beneficial for zone B, as fewer losses occur in that zone. In zone $\mathrm{D}$, however, the flow rises, and congestion can occur.

Case $\mathrm{C}$ depicts the situation where zone B sets its power flow device in such a way that there is a flow from zone A to zone $\mathrm{C}$. The flow through $\mathrm{D}$ has to compensate for this reverse flow and there is a resulting $10 \%$ loop flow. It is clear that this situation is not acceptable.

In case $\mathrm{D}$, there is an additional power flow controlling device installed in zone $\mathrm{D}$, which counteracts the device in $\mathrm{B}$. Note that this can be intentional (counteracting the system operator in B for a better utilization of the grid in D) or unintentional (since both system operators have different, local, objectives for the control of their local equipment). This situation could lead to two sunk investments, higher losses and lower reliability of the system.

This simple example states the need for coordination, not only between the devices within the given control area, but also cross-border. It is imperative that in order to have an efficient operation of the power system the power flow controlling devices need to be controlled to an objective that surmounts the local, national objectives.

It is agreed between the concerned TSOs that if Belgium makes a considerable switching action with its PSTs (and thus altering the flow through the Benelux and neighboring grids), the other TSOs are warned in advance. This allows them to take preventive coordinated actions. 


\section{B. HVDC lines}

Another power flow controlling device is a high voltage direct current line. A HVDC line enables to fully control the flow between its two terminals. Within the scope of this paper its effect on the meshed power system can be understood as a combination of a classic line with a phase shifting transformer added to it.

At both sides of the line, there is a converter station, which transforms the alternating current to direct current. While the losses of the cable are lower than in the classical line described in section 2, these converter stations cause additional losses. Relative short HVDC lines will thus have higher losses than the AC equivalent. Next to these extra losses and the installation costs, space for these converter stations is needed at both terminals.

In comparison to classical AC technology, HVDC has a number of applications where it is more effective. First of all it gives the opportunity to increase the capacity of an existing grid where additional lines do not offer a solution. Undersea cables typically uses HVDC technology. AC underground or undersea cables are technically very hard to realize; therefore HVDC can be a solution. Next to these two applications HVDC is very well suited for bulk power transfer over long distances, for example to connect remote areas (both load and generation), connecting asynchronous zones and stabilizing the grid.

In Belgium there are currently no HVDC lines installed, but it may be considered to use HVDC technology in two cases, a connection to the UK and to Germany, for increasing the cross border capacity.

1) Belgium-UK interconnection: If the UK and the European mainland need to be interconnected, HVDC is the only technical solution. A French-British interconnection, of $2000 \mathrm{MW}$, has been in operation for decades. BritNed, the newly planned Dutch British 1000 MW interconnection is now in permitting phase and the construction may start soon. The cost of BritNed is estimated at 600 million euro [8]. The Belgium-UK interconnection would be the third interconnection from the UK to the European continent.

2) Belgium-Germany interconnection: There is no interconnection with the German high voltage grid. In 2005 the concerned TSOs, Elia and RWE Transportnetz Strom, conducted a study about a possible cross-border interconnection between Belgium and Germany. Two technical scenarios were investigated, both were $\mathrm{AC}$ overhead lines in the form of a double $380 \mathrm{kV}$. They are thought to be infeasible since the total transfer capacity of Belgium would not be increased significantly. This is due to the meshed nature of the European high voltage network. The potential routes are both troublesome with either densely populated areas or natural reserves needed to be crossed. Only a classical upgrade of the grid, i.e. building AC lines, was investigated. Other solutions with power flow controlling devices could provide a solution in this case.
As a result it is considered to use a HVDC line to make a connection between Belgium and Germany. In [9] it is investigated what the impact of a HVDC connection is on the power flows in Belgium. Taking into consideration the evolution in generation and demand in future, different scenarios are simulated. The increase in cross border capacity depends on the choice of the connection point and varies amongst the different scenarios. It is shown that given current and future scenarios an increase of up to 1600 MVA in transfer capacity can be reached with multiple power flow controlling devices. However one has to bear in mind that the cost of this expensive connection is not limited to the cost of the cable itself. Apart from new substations at the terminals of the cable, several grid reinforcements are needed.

Both the connection to the UK and to Germany are in the study phase.

\section{DETERMINATION OF THE TRANSMISSION CAPACITY AVAILABLE FOR THE MARKET}

\section{A. The available transmission capacity}

In order to avoid overload or voltage stability problems, the Union for the Co-ordination of Transmission of Electricity (UCTE) and the European Transmission System Operators (ETSO) defined a method to calculate a maximum transfer capacity [10]. This capacity is published by ETSO twice a year in the form of a matrix with "Indicative values for Net Transfer Capacities (NTCs) in Europe" [11]. TSOs remain responsible for the calculation of these data and have to mutually agree on published data.

These indicative values are published every six months and are updated weeks and days before operation as more information (market behavior, planned outages, special event, etc.) becomes available. This capacity assessment is crucial in regions where congestion often occurs. Next to the indicative values of ETSO, each TSO define binding capacities.

Transactions between France and Germany, for example, which are in the same direction as the Belgian import, decrease the total import capacity of Belgium. Therefore prognoses of the generated wind power have to be taken into account. Even more local, depending on whether the French generation is closer to the north-east or the north-west border, defines which cross border line will get congested and thus limits the transfer capacity.

The same effects have to be taken into account during the planning phase of an investment in an additional cross-border line. Unfortunately it is hard to predict the future increase in available transfer capacity. This can be illustrated with a small actual example. The dutch TSO also decided to invest in phase shifters on its border with Germany in order to get more cross border capacity. This was around the same time that Belgium started planning for its own phase shifters. Time between planning and actual construction is quite long. In the mean time, additional wind power had been constructed in the north of Germany. This negatively influences the transfer capacity on the Dutch German border. The investment in the phase shifters, in this case, did not increase the transfer capacity on 
the Dutch-German border, but maintained it at the same level, offsetting the negative effect of the additional wind parks in Germany.

\section{B. Calculation Method}

The method for calculating the NTC values is explained in the Operation Handbook of UCTE [10]. (As is explained in the Operation Handbook of UCTE, this is one of the three methods applicable for calculating the indicative NTC values. Another method, referred to as Method B by UCTE, can be used in emergency cases, as generation limits are not taken into account. Method $\mathrm{C}$ is comparable but a merit order of generators is applied). The input data sets used in this method, reference cases, are snapshots taken on the third Wednesday of January and July. In this reference case, information on minimal and maximal output power of the generators are included. All calculations start from these reference cases. From this reference case, the power of all the generators in zone $\mathrm{A}$ is increased (together with an equal decrease in zone B).

$$
P_{n e w}^{i n c}=P_{i}+\Delta E \cdot \frac{P_{i}^{\max }-P_{i}}{\sum\left(P_{i}^{\text {min }}-P\right)}
$$

After an increase by $\Delta E$ a security check is performed, to verify whether the transmission network remains N-1 secure. It is up to each TSO to decide which grid elements have to be considered in the $\mathrm{N}-1$ analysis. In this $\mathrm{N}-1$ analysis, each TSO checks its own transmission grid, preferably extended with some neighboring nodes. If the security analysis does not discover any problem, $\Delta E$ can be applied again. When a constraint is met, $\Delta E_{\max }$ defines the TTC value.

This value is called the Total Transfer Capacity (TTC). From this TTC a Transmission Reliability Margin (TRM) is subtracted to obtain the NTC.

$$
N T C=T T C-R T M
$$

In a further capacity assessment, the available transmission capacity values (ATC values) are defined as the NTC value decreased by the already allocated capacity.

\section{CONCLUSION}

An overview is given on how cross-border capacity can be increased. Different technologies are available, but each has its advantages and disadvantages. Overhead lines and cables are the classic way to reinforce the grid. In some cases this offers a good opportunity and a relatively cheap way to increase the cross border capacity. Power flow controlling devices, such as phase shifting transformers and HVDC lines, offer a more clever solution to tackle the same problem. Therefore a careful analysis is needed, in order to obtain the aimed result. In this paper these different technologies have been discussed by considering some recent and in the near future planned grid investments in Belgium.

\section{ACKNOWLEDGEMENT}

The authors gratefully acknowledge financial support for the research reported in this paper by the IDO/04/004 project, granted by the University of Leuven (KULeuven) Research Council.

\section{REFERENCES}

[1] Elia, "Systeem- en marktoverzicht 2007," 2007. [Online]. Available: www.elia.be

[2] G. Küpper, E. Delarue, B. Delvaux, L. Meeus, D. Bekaert, B. Willems, S. Proost, W. D'haeseleer, K. Deketelaere, and R. Belmans, "Does more international transmission capacity increase competition in the Belgian electricity market?" The Electricity Journal, vol. 22, no. 1, pp. $21-36$, 2009. [Online]. Available: http://www.sciencedirect.com/science/article/ B6VSS-4VCNF10-2/2/3df465cef7185d963c8149566ddb15b2

[3] RTE, "Reinforcement of the France-Belgium interconnection," dec 2005. [Online]. Available: http://www.rte-france.com/htm/an/journalistes/ telecharge/dossiers/dp $\backslash$ france $\backslash \_$belgique $\backslash \_141205 \backslash$ ang.pdf

[4] Eurelectric, "Using underground technologies for high and very high voltage transmission links (150 kV and above) in Europe," mar 2004. [Online]. Available: http://www.eurelectric.org

[5] D. Van Hertem, "The use of power flow controlling devices in the liberalized market," Ph.D. dissertation, ESAT-ELECTA, K.U.Leuven, Belgium, 2009.

[6] J. Rimez, R. Van Der Planken, D. Wiot, G. Claessens, E. Jottrand, and J. Declercq, "Grid implementation of a 400 MVA 220/150 kV -15/+3 phase shifting transformer for power flow control in the Belgian network: specification and operational considerations," in Cigré sessions, 2006.

[7] ETSO, "2006-2007 winter review appendix: detailed country analysis," 2006. [Online]. Available: http://www.etso-net.org/upload/documents/ Winter $\backslash \% 20$ Review $\backslash \% 20$ Appendix $\backslash \%$ 20FINAL.pdf

[8] TenneT, "Britned kabel tussen Groot Brittanni en Nederland." [Online]. Available: http://www.tennet.org/projecten/BritNed/britned.aspx

[9] S. Cole, D. Van Hertem, and R. Belmans, "Connecting Belgium and Germany using HVDC: A preliminary study," in Power Tech 2007, 2007 IEEE Lausanne Powertech, Lausanne, Switzerland, 1 - 5 July 2007 2007, p. 5. [Online]. Available: www.esat.kuleuven.be/electa/ publications/fulltexts/pub_1692.pdf

[10] UCTE, "Operation handbook," Tech. Rep. [Online]. Available: www.ucte.org

[11] ETSO, "Indicative values for net transfer capacities (NTCs) in europe." [Online]. Available: http://www.etso-net.org 